\section{TEMPERATURE UNDER RADIANT INFANT WARMER: IS IT INFLUENCED BY THE UTILIZED DEVICE?}

D. Trevisanuto ${ }^{1}$, I. Coretti ${ }^{2}$, N. Doglioni ${ }^{1}$, A. Udilano ${ }^{2}$, R. Bacchin ${ }^{2}$, V. Zanardo ${ }^{1}$

${ }^{1}$ Pediatric Department, 2University of Padua, Azienda Ospedaliera di Padova, Padua, Italy

Objective: At birth, infants needing neonatal resuscitation are positioned under a radiant infant warmer (RIW) at $37^{\circ} \mathrm{C}$. We aimed to evaluate the performance of three different RIWs in a delivery room setting.

Methods: Temperatures were measured (Incu Fluke Biomedical, Bio-Tek Instruments, Everett, WA, USA) under 3 RIWs: (a) GE Healthcare PANDA i-RES, (b) Draeger Babytherm 8010 and (c) Fisher \& Paykel IW 930. Measurements were obtained at baseline, at 10 and 20 minutes after switching the power from 0 to $100 \%$ and maintaining the setting temperature constant at $24^{\circ} \mathrm{C}$.

Results:

\begin{tabular}{|l|c|c|c|c|}
\hline \multicolumn{1}{|c|}{ RIW } & $(\mathrm{a})$ & $(\mathrm{b})$ & $(\mathrm{c})$ & Anova \\
\hline Baseline & $\begin{array}{c}23.53 \pm \\
0.06\end{array}$ & $\begin{array}{c}24.10 \pm \\
0.36\end{array}$ & $\begin{array}{c}23.86 \pm \\
0.47\end{array}$ & 0.21 \\
\hline 10 & $4.73 \pm$ & $31.76 \pm$ & $37.46 \pm$ & $<0.01$ \\
minutes & 1.10 & 0.65 & 0.95 & \\
\hline 20 & $41.26 \pm$ & $35.30 \pm$ & $42.80 \pm$ & $<0.01$ \\
minutes & 0.25 & 0.20 & 0.20 & \\
\hline
\end{tabular}

[Table 1]

Conclusions: Temperature under RIW is significantly influenced by the utilized device. This aspect would be considered for management of neonates at birth.

\section{6}

\section{BORN AT 32-36 WEEKS - IS THIS A PROBLEM?}

\section{A.S. Birkelund, E. Garne}

Paediatric Department, Hospital Lillebaelt Kolding, Kolding, Denmark

Aim: To describe morbidity and mortality for infants born with GA 32-36 weeks in a Danish County.

Material and methods: Included were all infants with GA 32-36 weeks, born 2000-2006 and admitted to the neonatal unit at Hospital Lillebaelt. Data is from "Neobase" with data on treatment for all

admissions. Further data on survival by the end of 2009 was included. Total births in the county were 32339.

Results: The study included 1252 infants. Prevalence of births 32-36 weeks was 39 pr 1000 births. 447 infants (36\%) were from a multiple pregnancy. Twenty infants (1.6\%) died, 14 within the first week, 3 within 40 days and 3 within 6 months. The majority of infants $(17,85 \%)$ died with major congenital malformations.

More than half of the infants were delivered by Caesarean section (640,51\%). 465 infants (37\%) were treated with CPAP and 346 for more than 1 day. Fifty-one infants (4\%) received surfactant treatment and 6 of these died. 467 infants (37\%) received treatment for hypoglycemia and 289 needed glucose infusion. NEC was suspected clinically in only 1 infant.

Conclusions: $3.9 \%$ of all newborns in the population were admitted to the neonatal unit for treatment for moderate preterm birth. Infants born within GA 32-36 often need respiratory support. Mortality is much lower than for infants born with GA $<32$ weeks, where a similar study from the "Neobase" showed a mortality of $11 \%$, but higher than for term born infants. Mortality is mainly due to congenital malformations.

\title{
957
}

\section{USE OF THERAPEUTIC SURFACTANT LAVAGE} IN A PRETERM INFANT WITH MASSIVE PULMONARY HEMORRHAGE

\section{Kanavaki ${ }^{1}$, L. Vutskits ${ }^{2}$, P. Rimensberger ${ }^{1}$ \\ ${ }^{1}$ Pediatric and Neonatal Intensive Care Unit, Department of Pediatrics, ${ }^{2}$ Department of Anaesthesiology, Pharmacology and Intensive Care, University Hospital of Geneva, Geneva,} Switzerland

Introduction: Pulmonary hemorrhage $(\mathrm{PH})$ is a potentially life-threatening complication occurring in $10-16 \%$ of extremely low birth infants (ELBW), leading to chronic lung disease in $60 \%$ of cases. Surfactant is mainly used for early management of respiratory distress syndrome in preterm infants. Recently, therapeutic surfactant lavage with diluted surfactant has been proposed for the management of infants suffering from severe meconium aspiration syndrome (MAS). 